\title{
The Demographic Factor in the Sustainability of Spain's Pension System
}

\author{
Albert Esteve, Daniel Devolder and Amand Blanes, Centre d'Estudis Demogràfics.
}

The falling number of births, increased life expectancy and future retirement of the baby-boomers represent a challenge for the sustainability of the pension system in Spain because the relationship between contributors and pensioners is now smaller. In this issue of Perspectivas Demográficas we shall examine the impact of these factors on the demographic sustainability of the pension system and the effects that several scenarios of death rate, fertility and immigration might have in times to come. The demographic conditions of the past, which were very favourable to the system, will not be repeated in future. However, the coming demographic situation need not be an obstacle for maintaining a sustainable, solidary and adequate pensions system based on the idea of distribution (pay-as-you-go pension system).

\section{BY YOU TODAY, BY ME TOMORROW}

The pensions system in Spain is based on a solidary pact between generations. Economically active people make their contributions which, managed by Social Security, are used to pay the pensions of those people who in the past won the right to receive a life-long retirement pension. The sustainability of the system depends on the difference between the volume of contributions and that of pensions paid out, which in turn essentially depend on economic and demographic factors. Important among the economic elements are employment rates and wage levels, which are closely related with the productivity of the economy. Among the demographic variables, the most significant are the size and duration of birth cohorts. Size refers to the number of people constituting a cohort, which is the result of fertility/births in the past, mortality, and exits from and entries into the country as a result of migration. Duration refers to average lifetime from the time a cohort is born until all its members have died and, in terms of calculating pensions, from the time they retire until death. Size and duration condition the relationship between the economically active and retired populations. The greater the number of active

FIGURE 1. The demographic sustainability of the Spanish pension members of a population by comparison with retired members, the more sustainable the system. A persistent rise in life expectancy and stagnant or falling fertility (to below 1.5 children per woman) diminishes-and will continue to diminish-the relationship between active and retired members of the population which, at one point, was mitigated by the incorporation into the job market of the full generations born between 1960 and 1975, namely the babyboomers. Nevertheless, the approaching retirement of the babyboomers and the entry of empty generations into the job market have sounded alarm bells about the sustainability of the Spanish pension system and most western countries.

\section{THE DEMOGRAPHIC SUSTAINABILITY OF THE PENSION SYSTEM: PAST AND PRESENT}

The Demographic Sustainability Indicator (DSI) for the pension system measures the relation between the volume of contributions and the volume of retirement pensions in terms of demography (distribution by age and sex) at every point in time (Fig. 1). This

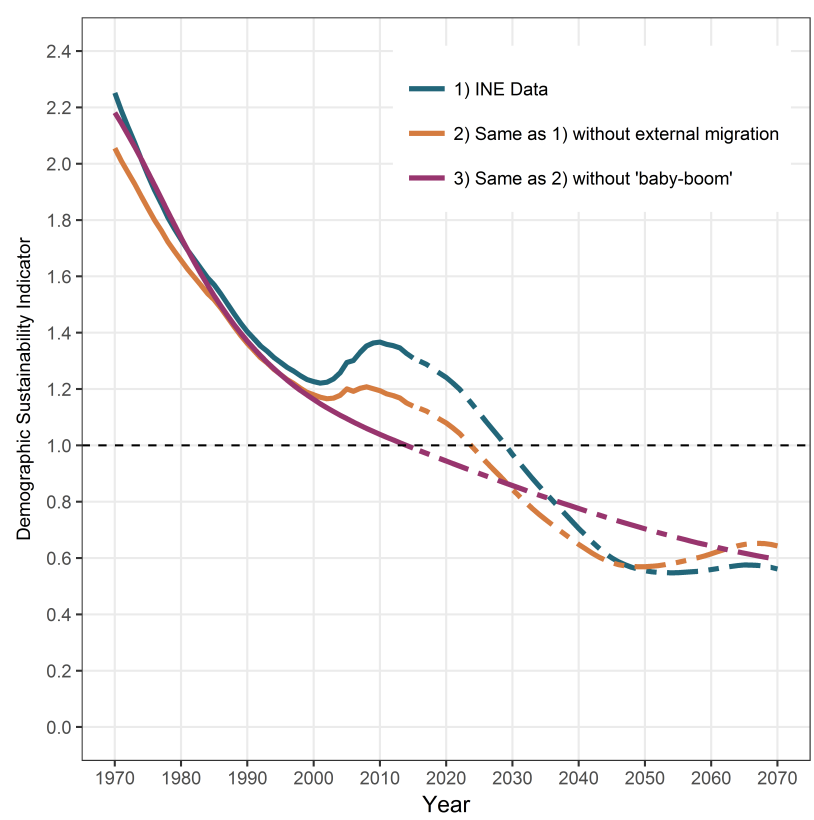

Source: INE data and own calculations. 
indicator takes on a constant economic profile over time. We assume here that the structure of earned income, employment and unemployment rates, contributions and pensions for 2012 is constant over time, retrospectively and prospectively. In this year, the average contribution represented $23 \%$ of wages and the value of the pension was, on average, $60 \%$ of the last pay packet. The system is sustainable (DSI is equal to or greater than 1) when the contributions paid in by the population are equal to or greater than the pensions being paid out to the population receiving a pension. Evidently, the absolute level of the indicator varies in accordance with the economic profile of reference but, in order to isolate the demographic effect, it is necessary to use a unique profile of reference. Hence, we shall focus more on the evolution of the indicator over time than on its absolute values.

Figure 1 shows the evolution of the DSI between 1970 and 2070 in accordance with three scenarios. The first scenario is based on the demographic evolution observed until 2015 while the projected part is based on the average scenario of forecasts published by the Spanish National Statistics Institute in 2016 (INE 2016). The second scenario asks what would have happened with the sustainability indicator without the international immigration to Spain in the last two decades. The third adds an additional supposition by substituting the baby-boom births with a moderate growth-trend evolution of births in the past. The three scenarios show that Spain has benefitted from demographic conditions that have been very favourable for maintaining the pension system. Assuming the 2012 economic profile, the contributions in 1970 would have amounted to double the amount required by the system to pay retirement pensions. However, between 1970 and 2000, the sustainability indicator dropped to 1.2 (where contributions are 20\% greater than pensions paid out). The fall in the indicator then stops and the level remains above 1.2 until 2025 thanks to the incorporation of the baby-boom generations into the job market and the arrival of international migrants. Without the baby boom and without international migrants, the demographic strains on the pension system would have been greater today and, to be specific, the DSI would have been $30 \%$ lower. It is important to note also that, from a strictly demographic standpoint, the sustainability of the system today is better than it was in 2000.

\section{TRENDS (AND DEMOGRAPHIC SOLU- TIONS?) IN THE SHORT AND MEDIUM TERMS}

The panels of Figure 2 show the demographic sustainability indicator forecast up to 2070 in keeping with different future scenarios on the evolution of mortality / life expectancy (panel 1), fertility (panel 2), and international migrations (panel 3). If mortality remained constant in the future at the 2015 level, the demographic sustainability of the pension system would drop to 0.72 in 2045 (contributions 28\% lower than pensions paid). If life expectancy rose in future at the rate of the last few decades the sustainability indicator would drop to 0.6 in 2045. Until 2045, 83\% of the decline in demographic sustainability is directly attributable to the effect of variation in the size of the cohorts that are retiring (the baby-boomers) and $17 \%$ to the increase in life expectancy (duration). This result is derived from comparing the decrease in DSI between 2015 and 2045 with and without rising life expectancy. In order to measure the impact of recovery in fertility on the

FIGURE 2. The future demographic sustainability of the Spanish pension system according to different scenarios regarding mortality, fertility and migration
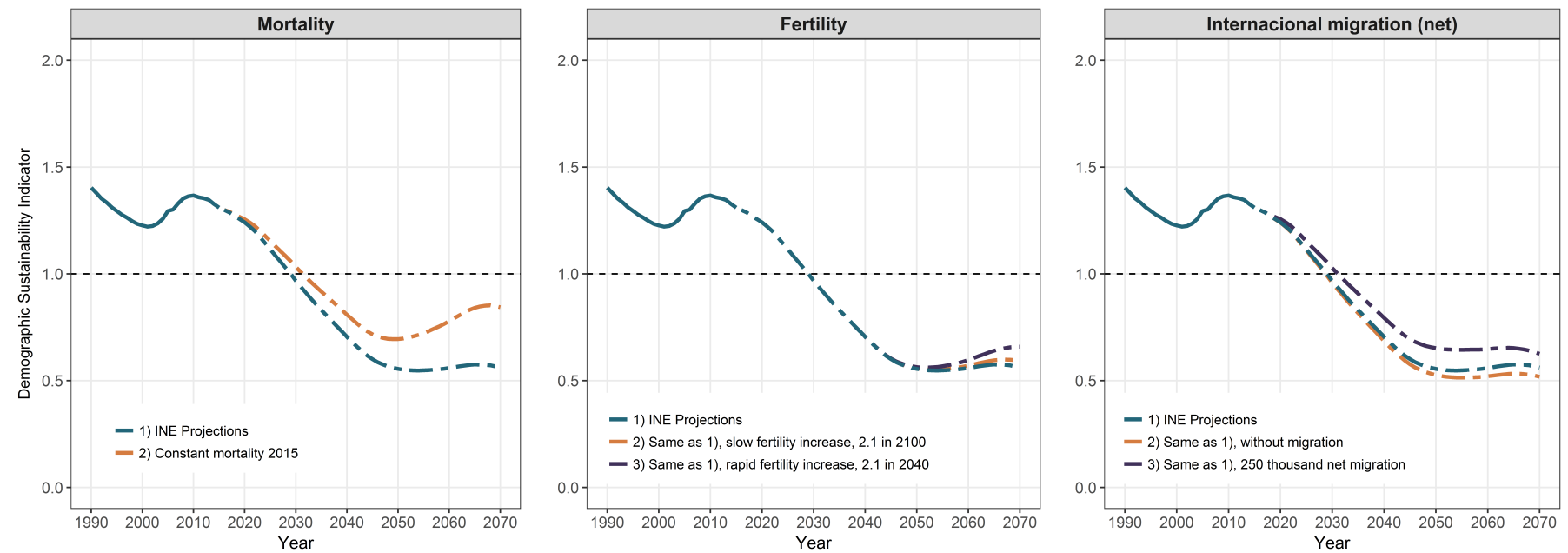

Source: INE data and own calculations 
demographic sustainability of the pension system, we consider two scenarios for increased fertility (see Figure 2, panel 2). In the first, fertility rises from 1.33 children per woman to 2.1 between 2016 and 2100 . In the second, fertility grows to 2.1 children per woman in 2040 and the flattens out at that level. The recovery of fertility has modest long-term effects on the demographic sustainability of the system. The effects are imperceptible before 2050. The express recovery of fertility (second scenario) slightly improves the sustainability of the system in 2070 although this would not be sufficient to reverse the decline.

In the short term, immigration has positive effects for the demographic sustainability of the system (see Figure 2, panel 3). Nevertheless, in the medium and long term, immigrants also retire. A steady increase of net migration from 12,00o people per year in 2016 to 80,000 in 2065, according to the INE forecast, would slightly improve sustainability indexes by comparison with the scenario of no growth in the number of immigrants. If the figure rose to 250,000 people per year, the indicator would increase by 10 points until 2050 (from 0.55 to 0.65 ). In the long term, which is to say by 2070 , no scenario is sufficient to reverse the drop in the sustainability indicator.

\section{RETIREMENT AGE}

AFrom a theoretical perspective, delaying retirement age is a simple way of guaranteeing the demographic sustainability of the pension system. This would lengthen the period for contributions and the retirement period would be shorter. Figure 3 shows the retirement age that would keep the system balanced according to two scenarios. The first scenario is based on the demographic conditions observed between 1970 and 2015, and those forecast by the INE until 2070. In 1970, thanks to the country's favourable demographic conditions, retirement age could have been set at 56.8 years, an age of 4.5 years lower that estimated for 2016. The full incorporation of the baby-boomers into the job market, in addition to the arrival of immigrants from other countries, would have made it possible to lower retirement age from 62.3 in 1999 to 60.7 in 2009, the year in which it would eventually begin to increase to reach 73.8 in 2058 . By then, all the baby-boomers would be retired. The oscillations observed in the retirement age in equilibrium reflect the entry into and exit from the job market by cohorts of different sizes.

The second scenario shows the evolution of retirement age in equilibrium in a population model that assumes the same mortality conditions of the first scenario but considers a stable growth in the number of births between -0,2\% and 0,2\% per year. This model
FIGURE 3. Optimal age at retirement to maintain equilibrium in the pension system according to different population scenarios

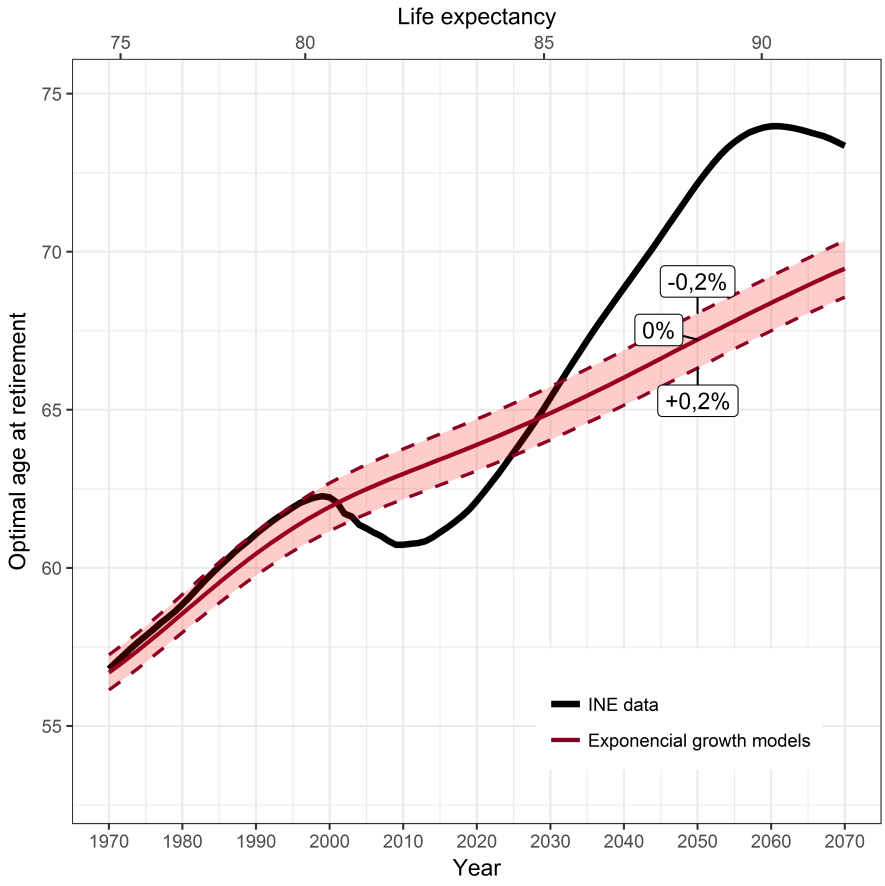

Source: INE data and own calculations

Note: The black line is based on the observed population until 2015 and INE population forecasts. The red line is based on a population model that accounts for increases in longevity but has no migration and no fluctuations in the number of births.

population, unlike the previous one, is not subject to sharp changes in the number of births owing, for example, to particular effects of the baby boom. Neither do they take into account exits and entries due to immigration. The difference in age at retirement between the lowest (-0.2\%) and highest (0.2\%) levels of growth is of 2 years. In this model, retirement age in equilibrium rises with gains in life expectancy. By 2030, retirement age in equilibrium would be 65 years in both scenarios. From that year onwards, the retirement of baby-boomers would push retirement age at higher levels than the ones needed in a population in which only gains in life expectancy would matter. By 2050, the difference between the two scenarios is 6 years.

\section{THE DEMOGRAPHIC VIABILITY OF THE SYSTEM: REFLECTIONS ON THE WHOLE}

In the last forty years, Spanish society has consolidated a pay-asyou-go pension system founded on favourable conditions that will not be repeated. These conditions have arisen from enduring growth of the economically active population with a relatively high retirement age in relation with the life expectancy levels of the period, and the retirement of small cohorts affected by higher mor- 
tality rates than the present ones. In view of the retirement of the baby-boomers, increased life expectancy, and the entry into the job market of empty generations, the future holds out radically different conditions. Accordingly, the future sustainability of the pension system can no longer depend on demography. Neither can it count on some improbable recovery-resulting from rising fertility or positive migration figures of increases of up to 250,000 newcomers per year-to reverse the effects on the system of the retirement of the baby-boomers and other effects related with increased life expectancy. However, this does not mean that future demography will be an obstacle for the viability of the pension system. Adjusting periods of contribution and retirement in accordance with life expectancy is a reasonable method for getting the numbers to tally. However, this adjustment should be based exclusively on gains in life expectancy and not the immediate needs of the system to get the numbers to work when faced with the retirement of larger or smaller generations. In effect, passing on the additional costs of pensions for the baby-boomers in measures for adjusting the system would clearly amount to intergenerational inequality..

In this exercise, we have intentionally left aside the impact of economic variations in the system in order to isolate clearly the effect of demographic change. Logically, if we modified the economic parameters, the levels of demographic sustainability of the pension system would vary. For example, according to our model, the increase of one percentage point in the level of contributions, in other words rising from $23 \%$ to $24 \%$ of the salary, would reduce the age of equilibrium at retirement by between 5 and 7 months, and would delay the point at which the system enters into deficit by between 3 and 5 years. The Spanish economy has ample opportunity

Bibliography

BLANES, Amand; CABRÉ, Anna (2015) "Inercias e incertidumbres en el futuro demográfico de España”. Revista del Ministerio de Empleo y Seguridad Social, 119 ("Seguridad Social"): 105-129.

FERNÁNDEZ CORDÓN, Juan Antonio (2015) "Relaciones intergeneracionales, demografía y economía en relación con las pensiones", Cuadernos de relaciones laborales, 33 (2): 235-258.

INSTITUTO NACIONAL DE ESTADÍSTICA (2016) "Proyecciones de la población de España, 2016-2066. Metodología”, Madrid, www.ine.es.

LEE, Ronald D; MASON, Andrew (2011) "Population Aging and the Generational Economy: A Global Perspective", Cheltenham, Edward Elgar. for improving its levels of productivity and employment. Increased employment and economic activity among young people and the population older than 60 years, or parity in male and female employment rates would have positive effects for the sustainability of the system in the short and medium terms. If the economy is able to capitalise on its assets, demography will place no obstacles in the way to ensuring the system's viability.

The demography of high levels of life expectancy, diminishing birth rates, population growth as a result of migratory movements, and pyramids transformed into obelisks is here to stay. Yet this does not mean that pay-as-you-go pension systems would not be sustainable in these conditions. It would require due adjustment of periods of work and retirement to the net increases in life expectancy in a way that is just and reasonable in accordance with the type of work and the effort made by past generations, independently of their size. Future sustainability demands improved productivity in the economy and changes in the system's financial provision. Otherwise, the citizens' trust in the pension system would be undermined. This would mean a challenge to the system of greater magnitude than that posed by demography.

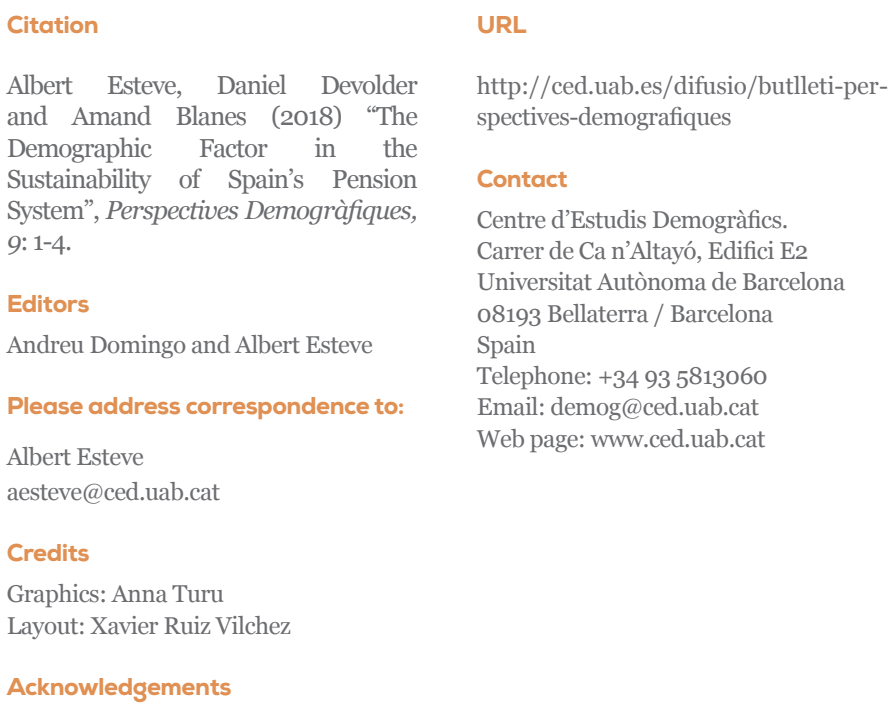

URL

http://ced.uab.es/difusio/butlleti-perspectives-demografiques

Contact

Centre d'Estudis Demogràfics.

Carrer de Ca n’Altayó, Edifici E2

Universitat Autònoma de Barcelona

o8193 Bellaterra / Barcelona

Spain

Telephone: +34935813060

Email: demog@ced.uab.cat

Web page: www.ced.uab.cat 